\title{
Experimental Identification of Optimized Process Parameters for FSW of AZ91C Mg Alloy Using Quadratic Regression Models
}

\author{
C. Satheesh. ${ }^{1}$ - P. Sevvel ${ }^{2}-$ R. Senthil Kumar ${ }^{2}$ \\ ${ }^{1}$ Madha Institute of Engineering and Technology, Department of Mechanical Engineering, India \\ ${ }^{2}$ S.A. Engineering College, Department of Mechanical Engineering, India
}

This experimental work aims to devise and establish quadratic regression equations, including various input criteria of a friction stir welding (FSW) technique to predict and determine the responses during the fabrication of AZ91C Mg alloy joints. The input process parameters taken into consideration include the traversing speed of the tool, the speed of rotation of the tool, its pin profile (geometry) and the axial force. A five-level, 4 four-factor composite design (of central nature) was applied, and response surface methodology (RSM) was used to formulate quadratic regression models, to develop 3D response surface charts, and to anticipate the responses for various mechanical properties. The generated quadratic mathematical model was tested and validated using the technique of analysis of variance. Validation experimental trial results outlined in the form of scatter diagrams revealed precedented coincidence with that of the generated models. The AZ91C Mg alloy joints obtained using the tool having taper cylindrical pin geometry employed at $1045 \mathrm{rpm}, 1.5 \mathrm{~mm} / \mathrm{s}$ traversing speed, under the exertion of an axial load of $4.87 \mathrm{kN}$ was found to exhibit improved mechanical properties.

Keywords: AZ91C Mg alloy, quadratic regression model, friction stir welding, tool pin geometry, tool rotational speed, ultimate tensile strength, tool traversing speed, axial force

Highlights

- An experimental endeavour was made to predict the ideal and optimized combination of input parameters of FSW technique to achieve maximized mechanical properties including yield, tensile strengths and percentage of elongation, through the employment of a statistically and mathematically advanced technique namely response surface methodology (RSM).

- The established quadratic regression model was efficient in determining the responses of the FSWed AZ91C Mg allot joints in the range of $+10 \%$ of their actual experimental values at a $95 \%$ level of confidence.

- 3D response surface charts illustrating the influence of input parameters on the mechanical properties and the direct impact plots representing the individual impact of these parameters on mechanical strength were generated and analysed in detail.

- AZ91C Mg alloy joints obtained using a tool having taper cylindrical pin geometry, employed at $1045 \mathrm{rpm}$, along a $1.5 \mathrm{~mm} / \mathrm{s}$ tool travelling speed, under the exertion of a $4.87 \mathrm{kN}$ axial force, were found to be free from flaws and naturally exhibited exceptional mechanical properties, especially higher values of ultimate tensile strength

- Six AZ91C Mg alloy joints were fabricated, employing the generated optimized input parameters. All the six joints were examined, and the observations revealed that they are completely free from defects, which proves their exact conformity with the generated values.

\section{INTRODUCTION}

Among the lightweight category materials, alloys of magnesium, especially AZ91C Mg alloy, are employed for an ample range of aerospace, automobile, and shipbuilding sectors, given their excellent specific strength, recyclability, higher values of specific stiffness, outstanding machinability, lower density values etc. [1] and [2]. However, at the same time, being a hexagonally closed packed structured metal, the slip structures of alloys of $\mathrm{Mg}$ are constrained concerning plastic deformation. Therefore, improving the ductility of $\mathrm{Mg}$ alloys (especially AZ91C) is an essential criterion for increasing the usage and applicability of these alloys to various industrial sectors [3] and [4]. It is a proven fact that the ductility and strength of the metals possessing hexagonal closed packed structures can be enhanced through the refinement of their grain structures. It is foreseen through various research works that the state of superplasticity will occur in these alloys if their grain size is reduced drastically [5].

AZ91C is a very common and popular $\mathrm{Mg}$ alloy, which is employed in nearly $85 \%$ to $91 \%$ of all the $\mathrm{Mg}$ cast components, due to its unique and excellent cast-ability properties, low cost, high levels of resistance to corrosion, etc. At the same time, its lower values of elongation property (arising due to the existence of coarse grains in its microstructure) have to be improved to make it applicable to various industrial sectors [6] to [8].With the objective of widening the application areas of this $\mathrm{AZ91C} \mathrm{Mg}$ alloys to several industrial sectors, various research initiatives [9] to [13] have been carried out broadly, primarily focusing on the improvement of the ductility of the AZ91C Magnesium alloys through the refinement of their grain structures. For instance, the $\mathrm{Mg}$ alloy $(\mathrm{Mg}-9 \mathrm{Al}-$ $1 \mathrm{Zn}$ ) was experimentally proved to exhibit higher 
levels of superplasticity at reduced temperatures, due to the employment of differential speed rolling process by Kim et al. [11]. This experimental investigation also revealed that, apart from the size of the grains, the microformability was also greatly influenced by the transition of superplastic flow to non-superplastic flow.

Compared to various plastic deformation improvement techniques, friction stir welding was very effective in fabricating high-quality aluminium similar and dissimilar joints, as the joining process takes place without their respective melting points. This fact was well proven by Khodabakhshi et al. [14] through his experimental investigation carried out during the friction stir processing of an $\mathrm{Al}-\mathrm{Mg}$ alloy (AA5052) sheet, employing the combination of Monte Carlo based simulation and modelling based on computational fluid dynamics modelling / Monte Carlo simulation to speculate the refinement of grains during that joining process. The parameters of friction stir welding (FSW) (i.e., speed of tool rotation and velocity of traverse) were taken as input parameters for formulating a numerical model for understanding the dynamic recrystallization of grains. The results reveals that the peak temperature was the preeminent factor in controlling the fabricated weldment's grain microstructure.

Recent research [15] to [23] carried out with respect to friction stir welding has demonstrated that improvement has taken place in the mechanical properties of Al alloy joints, due to the refinement of the grain structures and modifications in the microstructure of the welded regions. For example, the experimental work by Yuan et al. [17] investigated in detail the impacts of heat treatment (post weld) on the stability and formability of the friction stir welded tubes. The investigational results proved that the welded tubes' formability properties had been improved, because of the refinement of grains. It was proved through this investigation that the size of the subgrains and recipitates were controlled by this heat treatment process (carried out after the welding) and the stability of the microstructure is controlled by this heat treatment, which indirectly dominates the formability and strain hardenability of the friction stir welded tubes.

The practical possibility of employing friction stir welding for fabricating joints under the water was experimentally recorded by Derazkola et al. [19] during the joining of $\mathrm{Al}$ alloy (AA5083) sheets with Steel (AISI A441) sheets by submerging them under the water at three different temperatures: $50{ }^{\circ} \mathrm{C}, 25$ ${ }^{\circ} \mathrm{C}$, and $0{ }^{\circ} \mathrm{C}$. It was experimentally proven that, by reducing the cooling medium's temperature, the intermixing of the dissimilar metals was crumbled, leading to the generation of the intermetallic compound in the interface region. It was also found that the nugget zone's hardness was decreased due to the increased cooling ability of the submerged water medium. The precipitate distribution, size of the grains, and microhardness of the several regions of friction stir-welded T87 Al alloy was investigated by Liang et al. [20]. It was observed during this investigation that recrystallization occurred dynamically in the centre of nugget zone, and the grains in these regions are smaller in size when compared to that of the grains in the other weld zones. Moreover, the size of the precipitates was very much smaller in the heat zone when compared to that of the parent metal.

Another critical task in producing sound quality joint for any welding technique is directly related to the employment of ideal and optimal input parameters [24] and [25]. The specimens welded under different combinations of process parameters derived using the conventional techniques require an inspection to decide whether they meet the expected standards or not. These conventionally derived parameters are likely to fabricate joints nearer to the customer expectations; what is missed is the desirable combination of the optimized process parameters. In other words, alternative, better combinations of welding process parameters always exist, which can be employed, only if they can be determined. In this experimental investigation, an endeavour has been made to predict the ideal and optimized combination of input parameters of FSW technique to achieve maximized mechanical properties including yield, tensile strengths and percentage of elongation, through the employment of a statistically and mathematically advanced technique: response surface methodology.

\section{TECHNIQUE OF EXPERIMENTATION}

\subsection{Process Parameters Identification}

The material of our investigation is AZ91C Mg alloy and its chemical composition includes: $\mathrm{Al}-9.15 \%$; $\mathrm{Cu}-0.08 \% ; \mathrm{Zn}-0.859 \%$; Si $-0.119 \% ; \mathrm{Mn}-0.3$ $\%$; $\mathrm{Fe}$ and $\mathrm{Ni}-$ both less than $0.01 \%$ and $\mathrm{Mg}$ as the remaining percentage. The alloy's tensile strength was $287 \mathrm{MPa}$, along with a $191 \mathrm{MPa}$ Yield strength and percentage of elongation being 8.74. In an FSW technique, the parameters'(i.e., speed of rotation of the FSW tool) force applied from upwards, angle of tilt of the FSW tool, tool traverse velocity along weld line, shape of the tool pin profile, tool shoulder dimension 
Table 1. Description of employed process parameters, their levels and factors adopted in this experimental work

\begin{tabular}{clcccccc}
\hline $\begin{array}{c}\text { Sample } \\
\text { No. }\end{array}$ & Parameters of FSW & Symbol & \multicolumn{4}{c}{ Levels } \\
\cline { 4 - 7 } 1 & Geometry of tool pin & $P$ & $\begin{array}{c}\text { Straight } \\
\text { square }\end{array}$ & $\begin{array}{c}\text { Straight } \\
\text { cylindrical }\end{array}$ & $\begin{array}{c}\text { Threaded } \\
\text { cylindrical }\end{array}$ & $\begin{array}{c}\text { Taper } \\
\text { cylindrical }\end{array}$ & $\begin{array}{c}\text { Taper threaded } \\
\text { cylindrical }\end{array}$ \\
\hline 2 & Rotational speed [rpm] & $N_{R}$ & 500 & 650 & 800 & 950 & 1100 \\
\hline 3 & Tool traversing speed [mm/s] & $N_{T}$ & 0.5 & 0.75 & 1.00 & 1.25 \\
\hline 4 & Axial force $[\mathrm{kN}]$ & $F$ & 2 & 3 & 4 & 5 \\
\hline
\end{tabular}

and etc. are found to play determine the quality and the result of the entire process.

As it is practically impossible to identify and understand the influence of all the process parameters of FSW technique, the parameters that were reported and recorded (by several researchers) as most dominant and which seem to have a significant part in inducing the strength of the fabricated joints are presented in Table 1, along with their different levels.

Because of the broad spectrum of influence by the abovementioned process parameters during the fabrication of joints using FSW technique, a central composite design matrix comprising 31 trail runs, along with five levels, four factors of significance designed using the technique of response surface methodology. From Table 1, it can be understood that the maximum and minimum limit for these significant factors were assumed to be +2 and -2 , respectively.

\subsection{Description of Employed FSW Tools}

In this experimental investigation, the flat plates of cast AZ91C Mg alloy (5 $\mathrm{mm}$ thickness) were joined by FSW technique by employing tools with five different pin geometries (as mentioned in Table 1); straight square, taper cylindrical, straight cylindrical, taper threaded cylindrical and threaded cylindrical. The photographic illustration of these above-mentioned tools with five different pin geometries are shown in

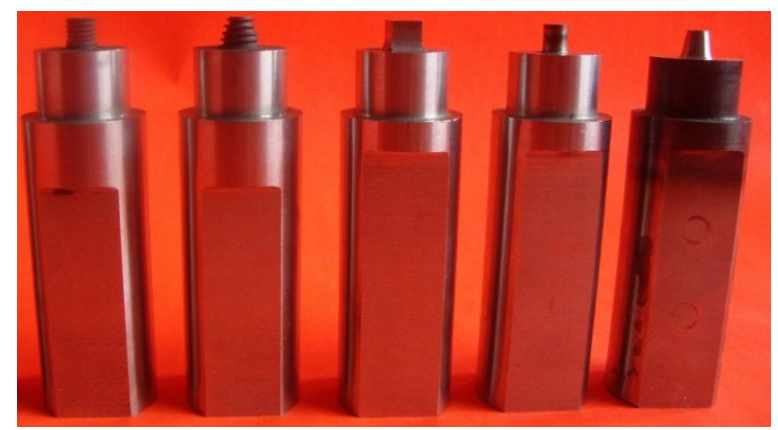

Fig. 1. FSW tools with five different pin geometries employed in this experimental investigation
Fig. 1. All these above-mentioned friction stir welding tools were fabricated using the M35 grade high-speed steel.

\subsection{Experimental Design Matrix and Investigational Runs}

Table 2 describes in detail the 31 sets of the experimental, investigational positions and their respective responses. The 31 experimental runs of the coded positions and conditions constitute a bisected replication of 16 factorial design (24) together with eight start (axial) points and points of the centre being 7. The points of the centre are constituted by the entire process parameters of the FSW placed at the levels of middle (i.e., 0). Simultaneously, the axial points are constituted by the combinations of individual FSW process parameters, either at their highest $(+2)$ value or at their least $(-2)$ value together with other four process parameters at their respective intermediate levels. Hence, these foresaid 31 investigational runs permit the evaluation of the quadratic equations and double-way interactive and collective impacts of these input parameters of FSW on the various responses (i.e., yield, tensile strength and percentage of elongation).

As indicated by the matrix of design of the response surface methodology, a total of 31 investigational runs were carried out employing the FSW technique and AZ91C Mg alloy FSW joints (Experimental run no. 31) were fabricated. During this process, the direction of joining was carried out in such a way that the travel direction of tool was assimilated to the direction of rolling of the AZ91C $\mathrm{Mg}$ alloy flat plates and each joint was obtained using a single pass. The photographic view of these fabricated AZ91C Mg alloy joints are shown in Fig. 2.

In this experimental and mathematical analysis, the material being employed for fabricating the tools for joining AZ80A Mg alloy flat plates is M35 grade high-speed steel (HSS). Tools with three distinctive pin geometries as shown in Fig. 1 are employed in this experimental work for fabricating the AZ80A Mg alloy joints using FSW technique. 
Table 2. Description of Design Matrix and their corresponding responses

\begin{tabular}{|c|c|c|c|c|c|c|c|c|c|c|c|c|c|c|c|}
\hline \multirow{2}{*}{$\begin{array}{c}\text { Experi- } \\
\text { mental } \\
\text { runs }\end{array}$} & \multicolumn{4}{|c|}{ Parameters } & \multicolumn{3}{|c|}{$\begin{array}{l}\text { Experimental } \\
\text { responses }\end{array}$} & \multirow{2}{*}{$\begin{array}{c}\text { Experi- } \\
\text { mental } \\
\text { runs }\end{array}$} & \multicolumn{4}{|c|}{ Parameters } & \multicolumn{3}{|c|}{$\begin{array}{l}\text { Experimental } \\
\text { responses }\end{array}$} \\
\hline & $P$ & $N_{R}$ & $N_{T}$ & $F$ & UTS & YS & $\begin{array}{l}\text { Percentage } \\
\text { of elongation }\end{array}$ & & $P$ & $N_{R}$ & $N_{T}$ & $F$ & UTS & YS & $\begin{array}{l}\text { Percentage } \\
\text { of elongation }\end{array}$ \\
\hline 1 & -1 & 1 & 1 & 1 & 190 & 93 & 3.71 & 17 & 0 & 2 & 0 & 0 & 226 & 130 & 4.25 \\
\hline 2 & 1 & 1 & 1 & -1 & 230 & 136 & 4.73 & 18 & 0 & 0 & 0 & 0 & 219 & 121 & 3.51 \\
\hline 3 & 0 & 0 & -2 & 0 & 210 & 117 & 3.70 & 19 & -1 & -1 & 1 & -1 & 181 & 82 & 3.05 \\
\hline 4 & 1 & 1 & -1 & -1 & 228 & 134 & 4.82 & 20 & 2 & 0 & 0 & 0 & 207 & 115 & 4.27 \\
\hline 5 & -1 & 1 & -1 & 1 & 185 & 90 & 3.65 & 21 & -2 & 0 & 0 & 0 & 148 & 51 & 2.12 \\
\hline 6 & 0 & 0 & 0 & 0 & 218 & 122 & 3.51 & 22 & 1 & -1 & -1 & 1 & 220 & 128 & 4.58 \\
\hline 7 & -1 & -1 & -1 & 1 & 182 & 84 & 3.02 & 23 & -1 & 1 & -1 & -1 & 187 & 90 & 3.64 \\
\hline 8 & -1 & -1 & -1 & -1 & 178 & 81 & 2.94 & 24 & 0 & 0 & 0 & 0 & 217 & 122 & 3.5 \\
\hline 9 & -1 & -1 & 1 & 1 & 184 & 87 & 3.05 & 25 & 1 & -1 & 1 & 1 & 223 & 130 & 4.83 \\
\hline 10 & 1 & -1 & 1 & -1 & 215 & 127 & 4.49 & 26 & 0 & 0 & 0 & 0 & 219 & 121 & 3.51 \\
\hline 11 & 0 & 0 & 2 & 0 & 213 & 119 & 3.91 & 27 & 0 & 0 & 0 & 0 & 217 & 120 & 3.52 \\
\hline 12 & 0 & 0 & 0 & 2 & 209 & 112 & 3.94 & 28 & 1 & -1 & -1 & -1 & 218 & 126 & 4.69 \\
\hline 13 & 1 & 1 & 1 & 1 & 238 & 143 & 5.05 & 29 & 0 & 0 & 0 & 0 & 217 & 122 & 3.5 \\
\hline 14 & 0 & -2 & 0 & 0 & 175 & 89 & 3.25 & 30 & 0 & 0 & 0 & 0 & 215 & 120 & 3.49 \\
\hline 15 & 1 & 1 & -1 & 1 & 229 & 135 & 4.98 & 31 & -1 & 1 & 1 & -1 & 186 & 89 & 3.5 \\
\hline 16 & 0 & 0 & 0 & -2 & 198 & 113 & 3.81 & & & & & & & & \\
\hline
\end{tabular}

\section{MATHEMATICAL MODEL}

\subsection{Correlation Equations}

Response surface methodology (RSM) is an assortment of rational, statistical and arithmetical approaches, applied for evaluating and investigating the problems in which a single response is influenced by a considerable amount of individual variables
[26] and [27]. The basic purpose and intention of employing RSM to an investigational problem are to determine and decide the exact arrangement and sequence of the parameters of a process, which will provide the best and excellent response value. Apart from this, the response surface methodology presents a model of regression, which portrays the connection between the responses and parameters of a process. This connection can be employed to anticipate the
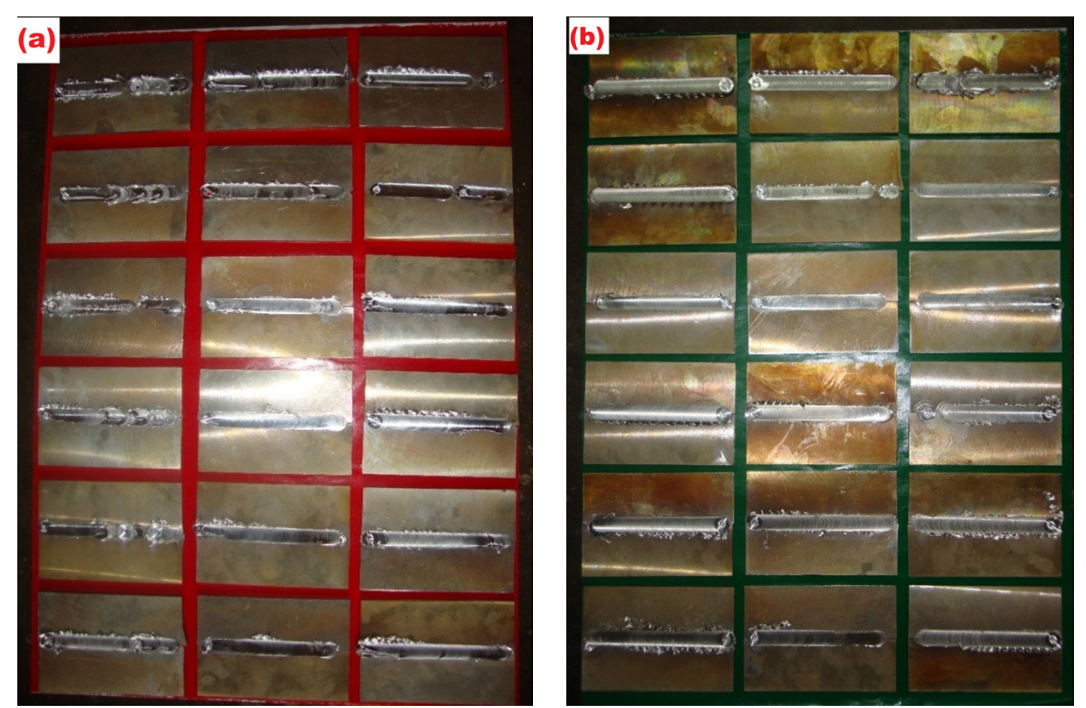

Fig. 2. AZ91C Mg alloy joints fabricated using the design matrix based experimental investigational runs) photos taken during the 1st part of experimental runs and b) photos taken during the $2^{\text {nd }}$ part of experimental runs 
response, whenever the parameters of an investigated process are diversified within the selected boundaries [28].

These regression models analytically describe the experimental surfaces, when the plot has been drawn for responses versus any two parameters of an investigational process. These generated plots make it feasible to understand the connections between the parameters and responses for a given experiment [29]. In our investigation, the response functions namely, yield strength, tensile strength (ultimate) and percentage of elongation of the fabricated joints are functions of input parameters namely, FSW tool pin geometry $(P)$, rotating speed of tool $\left(N_{R}\right)$, traversing speed of tool $\left(N_{T}\right)$ and force acting from the upward direction $(F)$.

They are expressed as:

$$
\begin{aligned}
U T S= & 217.43+(18.58 \cdot P)+\left(7.25 \cdot N_{R}\right)+\left(1.08 \cdot N_{T}\right) \\
& +(2.08 \cdot F)-\left(8.92 \cdot P^{2}\right)-\left(3.17 \cdot N_{R}{ }^{2}\right) \\
& -\left(0.42 \cdot N_{T^{2}}\right)-\left(2.42 \cdot F^{2}\right)+\left(1.62 \cdot P \cdot N_{R}\right) \\
& +\left(0.12 \cdot P \cdot N_{T}\right)+(0.62 \cdot P \cdot F)-\left(0.37 \cdot N_{R} \cdot \mathrm{F}\right) \\
& +\left(1.13 \cdot N_{T} \cdot F\right),
\end{aligned}
$$

Yield $=121.14+(20.46 \cdot P)+\left(6.13 \cdot N_{R}\right)$ $+\left(0.96 \cdot N_{T}\right)+(0.96 \cdot F)-\left(8.88 \cdot P^{2}\right)$

$$
\begin{aligned}
& -\left(2.25 \cdot N_{R}^{2}\right)-\left(0.13 \cdot N_{T}^{2}\right)-\left(1.50 \cdot F^{2}\right) \\
& +\left(0.56 \cdot P \cdot N_{R}\right)+\left(0.44 \cdot P \cdot N_{T}\right)+(0.06 \cdot P \cdot F) \\
& +\left(0.31 \cdot N_{R} \cdot N_{T}\right)-\left(0.06 \cdot N_{R} \cdot F\right) \\
& +\left(0.81 \cdot N_{T} \cdot F\right)
\end{aligned}
$$

Elongation $=3.506+(0.663 \cdot P)+\left(0.226 \cdot N_{R}\right)$

$$
\begin{aligned}
& +\left(0.021 \cdot N_{T}\right)+(0.053 \cdot \mathrm{F})-\left(0.013 \cdot P^{2}\right) \\
& +\left(0.126 \cdot N_{R}^{2}\right)+\left(0.139 \cdot N_{T}^{2}\right)+\left(0.157 \cdot F^{2}\right) \\
& -\left(0.091 \cdot P \cdot N_{R}\right)-\left(0.002 \cdot P \cdot N_{T}\right) \\
& -\left(0.002 \cdot P \cdot N_{T}\right)+(0.026 \cdot P \cdot F) \\
& -\left(0.018 \cdot N_{R} \cdot N_{T}\right)+\left(0.024 \cdot N_{R} \cdot F\right) \\
& +\left(0.046 \cdot N_{T} \cdot F\right) .
\end{aligned}
$$

\begin{tabular}{|c|c|c|c|c|c|c|c|}
\hline Source & $\mathrm{DF}$ & Seq SS & Contribution [\%] & Adj SS & Adj MS & $F$-Value & $P$-value \\
\hline Model & 14 & 12244.8 & 93.91 & 12244.8 & 874.63 & 17.61 & 0.000 \\
\hline Linear & 4 & 9682.0 & 74.25 & 9682.0 & 2420.50 & 48.73 & 0.000 \\
\hline$P$ & 1 & 8288.2 & 63.56 & 8288.2 & 8288.17 & 166.87 & 0.000 \\
\hline$N_{R}$ & 1 & 1261.5 & 9.67 & 1261.5 & 1261.50 & 25.40 & 0.000 \\
\hline$N_{T}$ & 1 & 28.2 & 0.22 & 28.2 & 28.17 & 0.57 & 0.462 \\
\hline$F$ & 1 & 104.2 & 0.80 & 104.2 & 104.17 & 2.10 & 0.167 \\
\hline Square & 4 & 2485.3 & 19.06 & 2485.3 & 621.32 & 12.51 & 0.000 \\
\hline$P \cdot P$ & 1 & 2072.1 & 15.89 & 2275.1 & 2275.08 & 45.80 & 0.000 \\
\hline$N_{R} \cdot N_{R}$ & 1 & 244.9 & 1.88 & 287.3 & 287.29 & 5.78 & 0.029 \\
\hline$N_{T} \cdot N_{T}$ & 1 & 0.8 & 0.01 & 5.0 & 5.04 & 0.10 & 0.754 \\
\hline$F \cdot F$ & 1 & 167.4 & 1.28 & 167.4 & 167.42 & 3.37 & 0.085 \\
\hline 2-Way Interaction & 6 & 77.5 & 0.59 & 77.5 & 12.92 & 0.26 & 0.948 \\
\hline$P \cdot N_{R}$ & 1 & 42.2 & 0.32 & 42.2 & 42.25 & 0.85 & 0.370 \\
\hline$P \cdot N_{T}$ & 1 & 0.2 & 0.00 & 0.2 & 0.25 & 0.01 & 0.944 \\
\hline$P \cdot F$ & 1 & 6.2 & 0.05 & 6.2 & 6.25 & 0.13 & 0.727 \\
\hline$N_{R} \cdot N_{T}$ & 1 & 6.2 & 0.05 & 6.2 & 6.25 & 0.13 & 0.727 \\
\hline$N_{R} \cdot F$ & 1 & 2.2 & 0.02 & 2.2 & 2.25 & 0.05 & 0.834 \\
\hline$N_{T} \cdot F$ & 1 & 20.3 & 0.16 & 20.3 & 20.25 & 0.41 & 0.532 \\
\hline Error & 16 & 794.7 & 6.09 & 794.7 & 49.67 & & \\
\hline Lack-of-Fit & 10 & 783.0 & 6.00 & 783.0 & 78.30 & 40.10 & 0.000 \\
\hline Pure Error & 6 & 11.7 & 0.09 & 11.7 & 1.95 & & \\
\hline Total & 30 & 13039.5 & 100.00 & & & & \\
\hline
\end{tabular}

\subsection{Confirming the Competence of Established Model}

The competency of the generated and proposed mathematical model is analysed by employing the ANOVA approach, and the outcomes of the $2^{\text {nd }}$ order response surface model were found to coincide with the output models of ANOVA (analysis of variance). Results of ANOVA for the response functions (i.e., tensile strength (ultimate) and yield strength of the fabricated joints) are indicated in the Tables 3 and 4, respectively.

Table 3. Results of ANOVA for response functions of tensile strength (ultimate)

Model Summary: S - 7.04767; R - Sq: $93.91 \%$ 
Table 4. Results of ANOVA for response functions of yield strength

\begin{tabular}{|c|c|c|c|c|c|c|c|}
\hline Source & DF & Seq SS & Contribution [\%] & Adj SS & Adj MS & $F$-Value & $P$-Value \\
\hline Model & 14 & 13347.8 & 95.96 & 13347.8 & 953.4 & 27.14 & 0.000 \\
\hline Linear & 4 & 10989.5 & 79.00 & 10989.5 & 2747.4 & 78.20 & 0.000 \\
\hline$P$ & 1 & 10045.0 & 72.21 & 10045.0 & 10045.0 & 285.93 & 0.000 \\
\hline$N_{R}$ & 1 & 900.4 & 6.47 & 900.4 & 900.4 & 25.63 & 0.000 \\
\hline$N_{T}$ & 1 & 22.0 & 0.16 & 22.0 & 22.0 & 0.63 & 0.440 \\
\hline$F$ & 1 & 22.0 & 0.16 & 22.0 & 22.0 & 0.63 & 0.440 \\
\hline Square & 4 & 2338.0 & 16.81 & 2338.0 & 584.5 & 16.64 & 0.000 \\
\hline$P$ & 1 & 2144.8 & 15.42 & 2254.6 & 2254.6 & 64.18 & 0.000 \\
\hline$N_{R}$ & 1 & 128.4 & 0.92 & 145.3 & 145.3 & 4.14 & 0.059 \\
\hline$N_{T}$ & 1 & 0.0 & 0.00 & 0.5 & 0.5 & 0.01 & 0.908 \\
\hline$F$ & 1 & 64.7 & 0.47 & 64.7 & 64.7 & 1.84 & 0.194 \\
\hline 2-Way Interaction & 6 & 20.4 & 0.15 & 20.4 & 3.4 & 0.10 & 0.996 \\
\hline$P \cdot N_{R}$ & 1 & 5.1 & 0.04 & 5.1 & 5.1 & 0.14 & 0.709 \\
\hline$P \cdot N_{T}$ & 1 & 3.1 & 0.02 & 3.1 & 3.1 & 0.09 & 0.772 \\
\hline$P \cdot F$ & 1 & 0.1 & 0.00 & 0.1 & 0.1 & 0.00 & 0.967 \\
\hline$N_{R} \cdot N_{T}$ & 1 & 1.6 & 0.01 & 1.6 & 1.6 & 0.04 & 0.836 \\
\hline$N_{R} \cdot F$ & 1 & 0.1 & 0.00 & 0.1 & 0.1 & 0.00 & 0.967 \\
\hline$N_{T} \cdot F$ & 1 & 10.6 & 0.08 & 10.6 & 10.6 & 0.30 & 0.591 \\
\hline Error & 16 & 562.1 & 4.04 & 562.1 & 35.1 & & \\
\hline Lack-of-Fit & 10 & 557.2 & 4.01 & 557.2 & 55.7 & 68.84 & 0.000 \\
\hline Pure Error & 6 & 4.9 & 0.03 & 4.9 & 0.8 & & \\
\hline Total & 30 & 13909.9 & 100.00 & & & & \\
\hline \multicolumn{8}{|c|}{ Model Summary: $S$ - 5.92720; $R-$ Sq: $95.96 \%$} \\
\hline
\end{tabular}

If the obtained value of $F_{\text {ratio }}$ of the developed model is lower than the definitive $F_{\text {ratio }}$ value at a named $95 \%$ to $96 \%$ certainty level, the established and predicted model will be competent with the level of confidence. The value of probability $>F$ for the three established models is less than the value of 0.05 (i.e., $95 \%$ level of confidence), which indirectly proves that the developed model is satisfactory. The predicted values versus the actual experimental values for the responses of the developed regression equations are graphically in Fig. 3, which reveals the presence of an exceptional interrelationship between the predicted value of the generated responses and the actual experimental values. In these graphs, it can be seen that the distributed and scattered plots are very much nearer to the $45^{\circ}$ line, which shows the flawless fitness of the predicted mathematical relationship [30].

\section{OUTCOMES, VALIDATION, AND DELIBERATION}

\subsection{Micro and Macrostructural Analysis}

Fig. 4 illustrates the macrographical image of a crosssection of the sound quality welded specimen taken horizontally to the FSW tool's travelling direction. The nugget zone of this welded specimen is found to be completely free from various defects, such as porosity, tunnel voids, excessive flash, kissing bond defects, defective tightness, onion skin microstructures, cracksimilar root flaws, etc. [31] to [33].

Fig. 5 describes in detail the microstructure of the parent metal and different zones (heat-affected portion (zone) (HAZ), thermos mechanically affected portion (zone) (TMAT) and nugget zone (NZ) of the defectfree welded specimen. It can be visualized from these microstructures that $\mathrm{AZ91C} \mathrm{Mg}$ alloy contains large coarse sized grains, unevenly distributed over the entire region.

However, at the same time, from the micrographs of the various regions of the defect-free FSWed specimen, especially in the nugget zone, the grains are found to be completely transformed into fine-sized, uniformly distributed, equally spaced grain structures. This transformation of grains has taken place, because of the ideal up-roaring action and force of tool pin geometry, which has generated recrystallization of grains in a dynamic manner [34] and [35].

Based on the careful observation of these simulated temperature contour graphs, we can infer that performing the joining of AZ80A Mg alloys by 

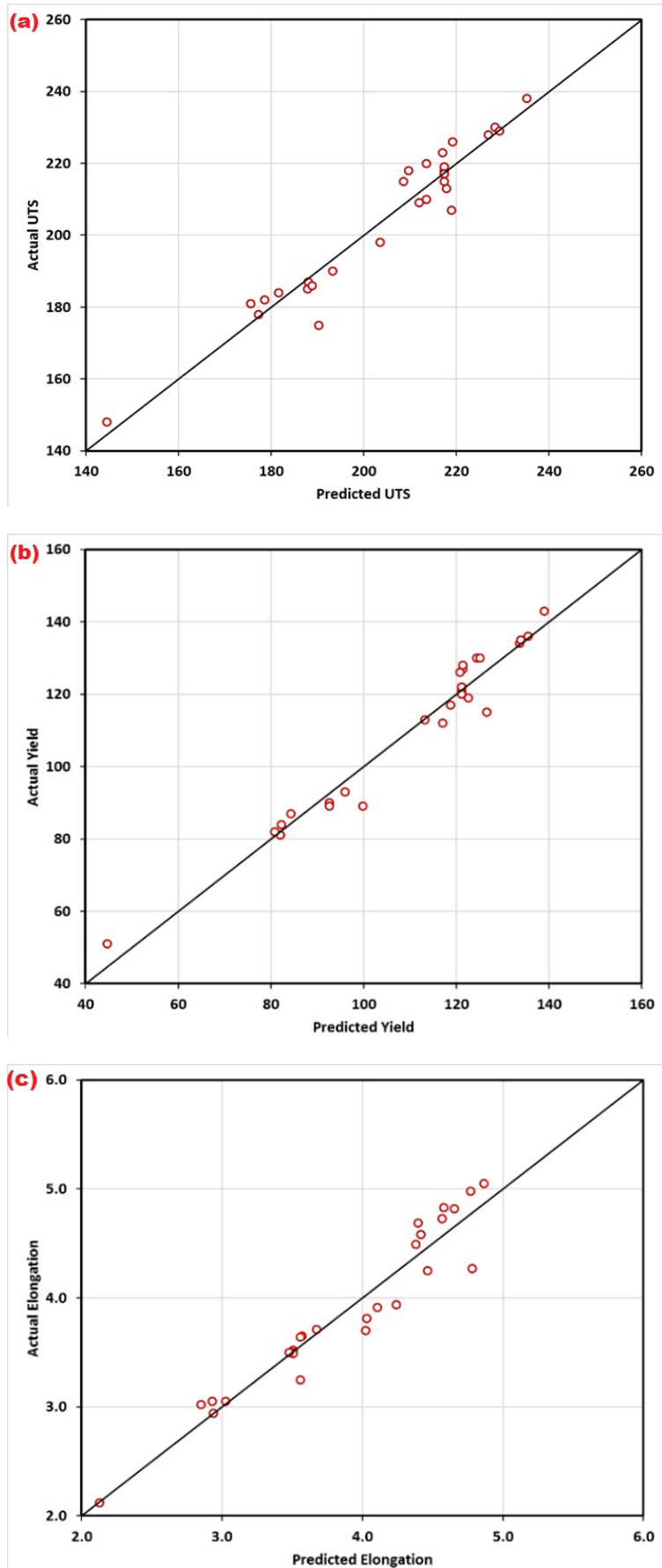

Fig. 3. Graphical representation of the predicted values of the responses vs actual experimental values for a) actual vs. predicted ultimate tensile strength; $b$ ) actual vs. predicted yield strength and c) actual vs. predicted percentage of elongation

FSW, at an optimized combination of higher rotational speeds of FSW tool, with the FSW tool traversing at low speeds and by applying larger values of axial load, will result in the generation of the ideal peak temperature, which will eventually contribute to perfect bonding between the AZ80A Mg alloy plates to be welded, thereby resulting in sound quality weldments. In addition to this, the employed taper cylindrical pin profile also has contributed to a greater extent in fabricating these sound quality weldments. This is because tapered tool pin profiles are always found to exhibit eccentricity. This eccentricity allows the smooth flow of the plasticized material around the tool pin profile region, thereby leading to the generation of a efficient stirring action, thereby contributing towards homogenous, finely spaced and refined grain structures in the zone of nugget [36] and [37].

\subsection{Impact on Mechanical Properties}

Fig. 6 illustrates the three-dimensional (3D) response surface charts for the tensile strength, plotted using the developed mathematical models. The maximum values of the responses are indicated by the apex of the surfaces of responses. From these graphs, the impingement of the several input parameters on the mechanical strength of the welded specimen can be easily visualized. For example, from Fig. 6c, it is visible that the mechanical strength of the welded joints has increased with the simultaneous increase in the tool traversing speed and rotational speed of the tool. It can also be visualized that the higher the rotating speed of FSW tool is, the larger is the tensile strength of the welded joint.

From these graphs, it can be understood that the ultimate strength of tensile is lower at low rotating speeds (500 rpm, $650 \mathrm{rpm}$, etc.) and reaches its maximum value at higher speeds of rotational speed (1000 rpm to $1100 \mathrm{rpm}$ ). Similarly, greater values of tensile strength are exhibited at higher traversing speed of the FSW tool $(1.0 \mathrm{~mm} / \mathrm{s}$ to $1.5 \mathrm{~mm} / \mathrm{s})$. At the same time, the moderate amount of axial force $(4 \mathrm{kN}$ to $5 \mathrm{kN})$ and the tool with taper cylindrical pin geometry are found to display higher values of tensile strength in combination with the above-mentioned process parameters.

Fig. 7 illustrates the 3D response surface charts for other mechanical properties obtained using the developed mathematical models. From these graphs, the impingement of several input parameters on the yield strength and percentage of elongation of the fabricated joints can be visualized easily. From these graphs, it is evident that the tool with taper cylindrical pin geometry exhibits defect-less AZ91C joints. This is mainly due to the ideal up-roaring action and the force of tool's taper cylindrical pin geometry, which 


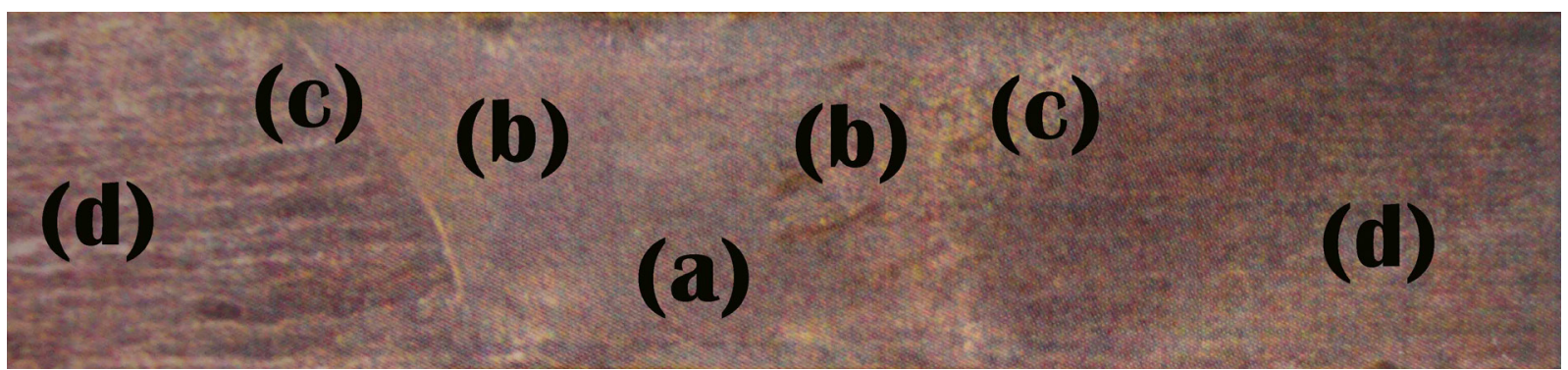

Fig. 4. Optical macrograph of the cross-section of the fabricated high strength tensile specimen, indicating the various zones of the friction stir welded region namely; a) nugget region; b) thermo-mechanically transformed region; c) heat-affected region, and d) unaffected parent metal
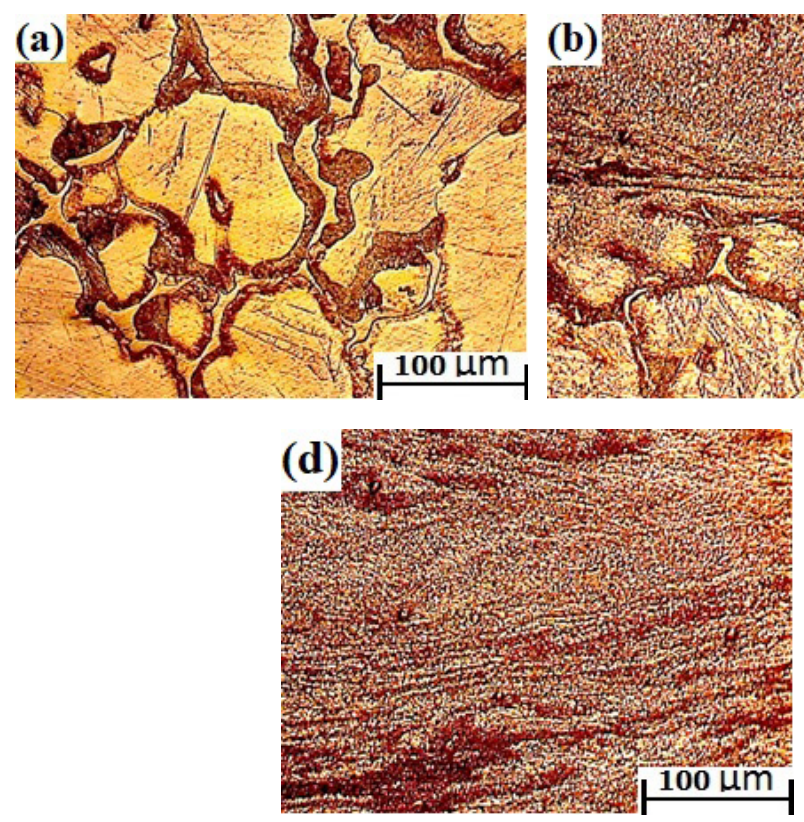
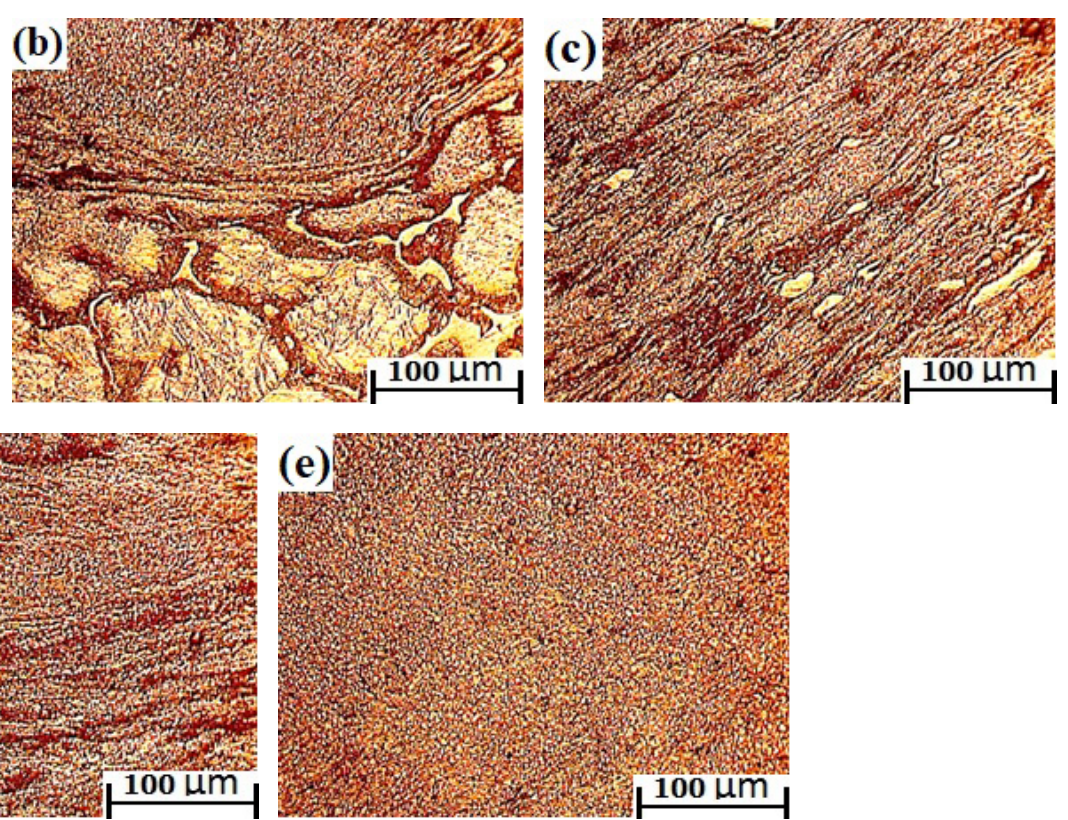

Fig. 5. Microstructures of a) AZ91C Mg alloy and various portions of the defect-free joint including, b) AZ91Cportion influenced by the up roaring force of tool shoulder, c) heat-affected portion, d) thermo-mechanically affected portion, and e) centre of the nugget zone

have caused the grains to undergo severe plastic deformation.

The combination of this tapered pin geometry along with a high tool rotating speed (1000 rpm to $1100 \mathrm{rpm}$ ) have generated an ideal volume of heat, leading to an appreciable amount of plastic shear deformation, which has transformed the unequally sized grains of parent metal into uniaxial, radical, homogeneous uniformly distributed and equispaced fine grains, as seen in Fig. 6.

Likewise, from the 3D response surface plots, we can understand that the process parameters (i.e., axial force and the tool's traversing speed) also play a vital role in deciding the strength of the welded joints. It is seen from these graphs that, the material flow in the zone of the nugget of the fabricated joints are dominated by the purge process during which the applied amount of force (axial) and the traversing speed of tool together push the plasticized substances, after the occurrence of severe plastic deformation.

The employment of lower values of axial force ( $2 \mathrm{kN}$ and $3 \mathrm{kN}$ ) along with lower tool traversing speeds $(0.5 \mathrm{~mm} / \mathrm{s}$ to $1.25 \mathrm{~mm} / \mathrm{s})$ have resulted in the generation of low peak temperatures in the nugget regions leading to incomplete dynamic recrystallization. This inappropriate combination has resulted in the fabrication of AZ91C joints with various defects leading to lower tensile strength values $(189 \mathrm{kN}$ to $207 \mathrm{kN})$ and lower yield strength values $(100 \mathrm{kN}$ to $114 \mathrm{kN})$.

When an sufficient amount of axial force $(4 \mathrm{kN}$ to $5 \mathrm{kN}$ ) is applied during FSW of AZ91C joints on taper cylindrical pin profiled tool, along with suitable combination of $1000 \mathrm{rpm}$ to $1100 \mathrm{rpm}$ (rotating 

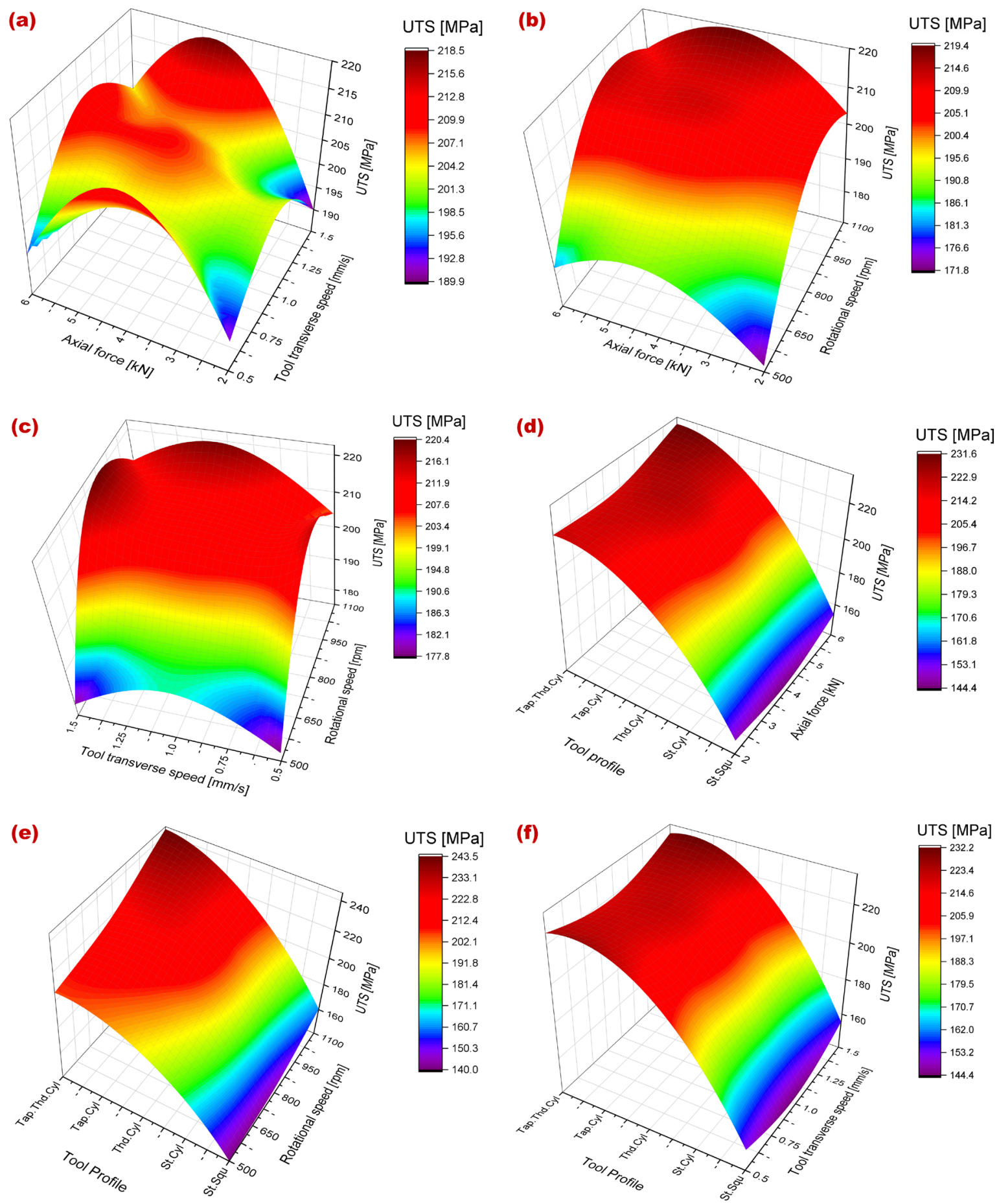

Fig. 6. 3D response charts illustrating the impact of a) axial force and tool traversing speed, b) axial force and rotating speed, c) tool traverse speed and rotating speed, d) tool pin profile and axial force, e) geometry of tool pin and rotational speed, and f) tool pin geometry and tool traverse speed on Tensile strength of welded joints

speed), by making the FSW tool to travel in the range of $1.3 \mathrm{~mm} / \mathrm{s}$ to $1.5 \mathrm{~mm} / \mathrm{s}$, the frictional heat was found to be generated in ideal and sufficient volumes, which directly contributes to the appreciable rise in the heat input, leading to preferable amount of plastic deformation, thereby accelerating the grain growth, 
(a)

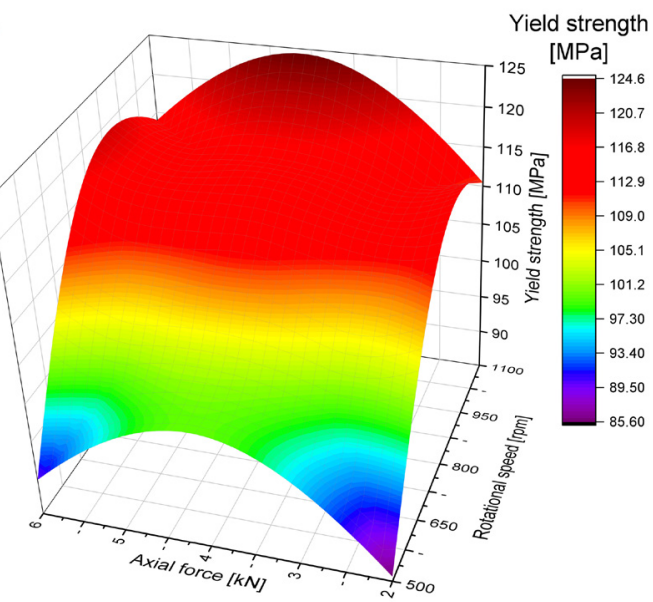

(c)

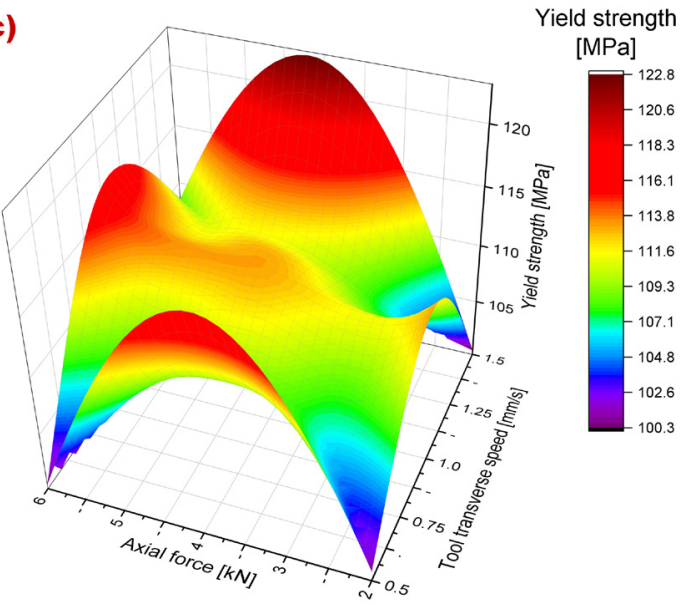

(e)

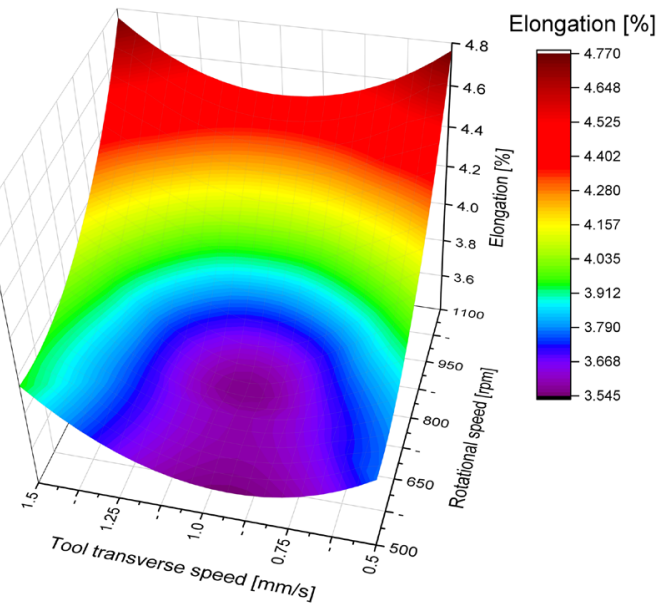

(b)

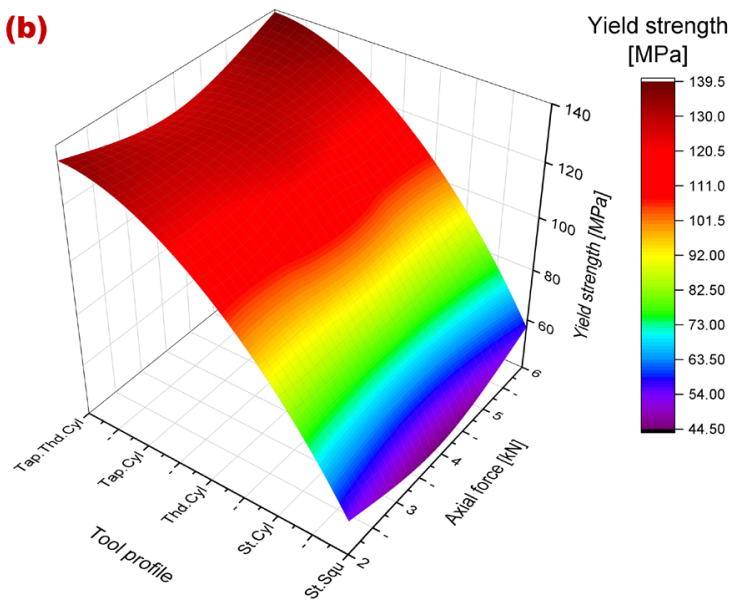

(d)

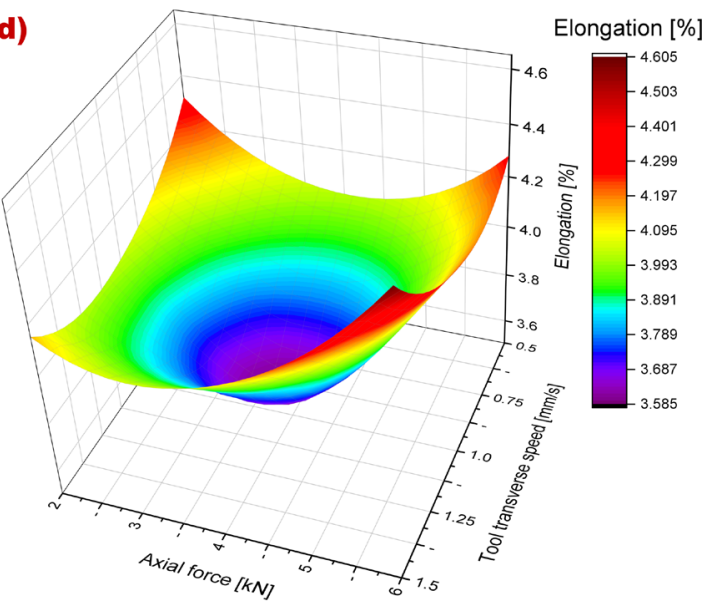

(f)

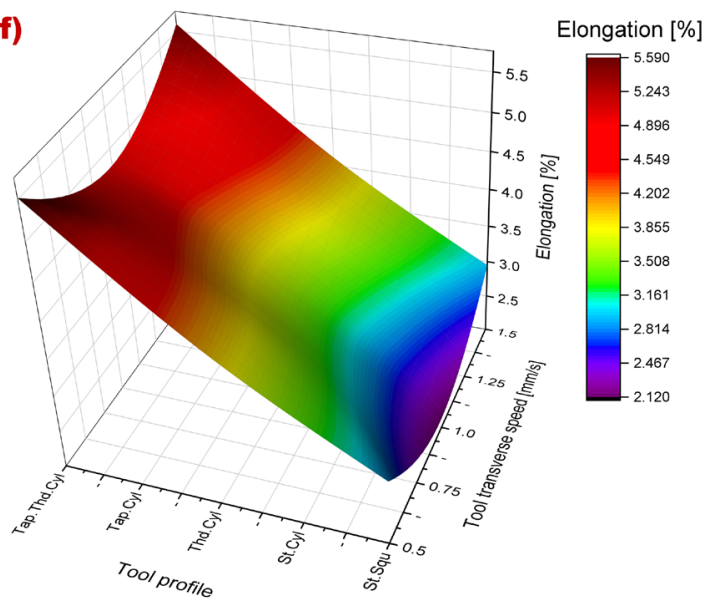

Fig. 7. 3D response charts illustrating the impact of a) axial force and tool traversing speed, b) axial force and rotating speed, c) tool traverse speed and rotating speed on Yield strength, d) tool pin profile and axial force, e) geometry of tool pin and rotational speed, and f) tool pin geometry and tool traverse speed on percentage of elongation

causing the transformation of unequally, large-sized grains into uniaxial, radical, homogeneous uniformly distributed and equispaced fine grains.

\subsection{Analysis of SEM Images}

By observing Fig. 8a, we can visualize the presence of massive sized, coarse and irregularly distributed 

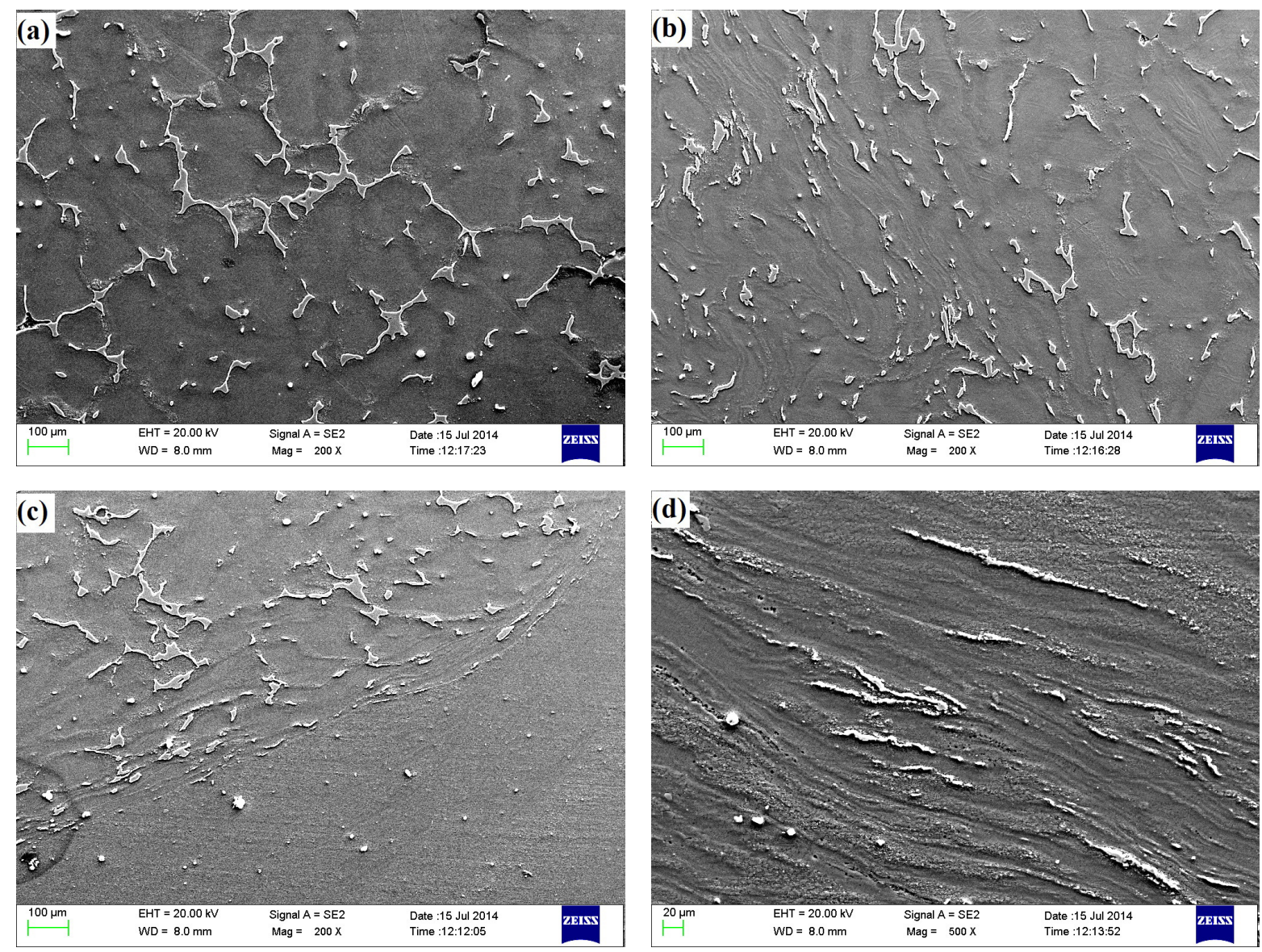

Fig. 8. SEM images of a) AZ91C Mg alloy, b) first interface region of the base metal and the nugget zone, c) thermo mechanically transformed region, and d) center of the nugget region

grains containing $\mathrm{Al}_{12} \mathrm{Mg}_{17}$ intermetallic type aggregates. Concurrently, the observation of the scanning electron micrograph (SEM) pictures of the successfully fabricated AZ91C weldments (especially heat affected zone), as seen in Fig. 8b, reveals that the stirring process and force exerted by the taper cylindrical pin profiled tool have completely deliquesced the aggregates of $\mathrm{Al}_{12} \mathrm{Mg}_{17}$, and the ideal volume of generated heat (resulting from the suitable combination of the above mentioned FSW process parameters) have directed the plastically deformed grains along the axes of rotation.

The $\mathrm{Al}_{12} \mathrm{Mg}_{17}$ precipitates (white particles) have been found to be elongated and fragmented. Fig. $8 \mathrm{c}$ shows the thermos mechanically transformed region, where the grains of the parent metal have changed their direction, the precipitates are fragmented, and it is completely influenced by up-roaring action and force of tool pin geometry. Likewise, as seen in Fig. 8d, the grain matrices of the AZ91C $\mathrm{Mg}$ alloy have also been found to undergone complete plastic deformation exactly along the FSW tool axis and the nugget zone is found to possess fine-sized, homogeneous, uniformly distributed grains [38].

Energy-dispersive X-ray spectroscopy (EDX) images of the centre of nugget zone of the fabricated weldment (as illustrated as SEM image in Fig. 8d) is illustrated in the Fig. 9 and from this figure, the presence of intermetallics can be understood clearly.

\subsection{Determination of Optimized Process Parameters}

By analysing and visualizing these 3D response surface plots and the SEM images of the defectfree fabricated weldments, it is evident that the collaborative and collective impact of the axial force, traversing speed and rotating speed of tool have played a vital role in improving the tensile strength, resulting in AZ91C welded specimen, which are experimentally proven to be flawless. The various anticipated values of the mechanical properties are determined using 


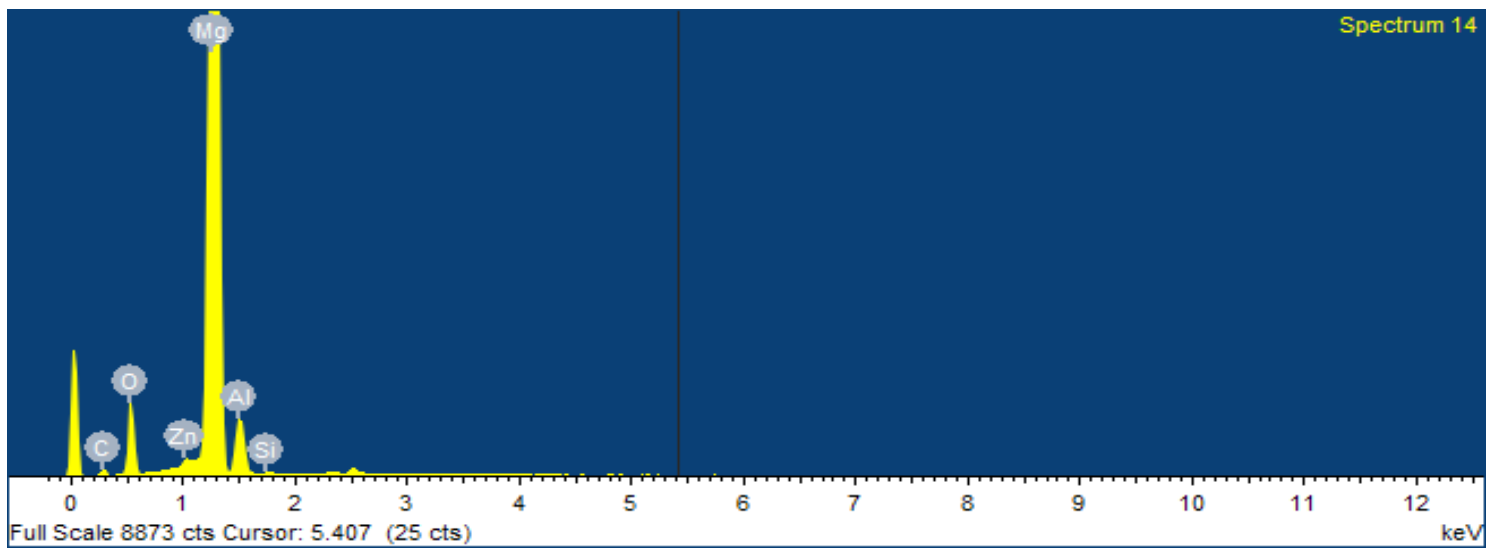

Fig. 9. EDX images of the center of nugget zone of the fabriated weldment

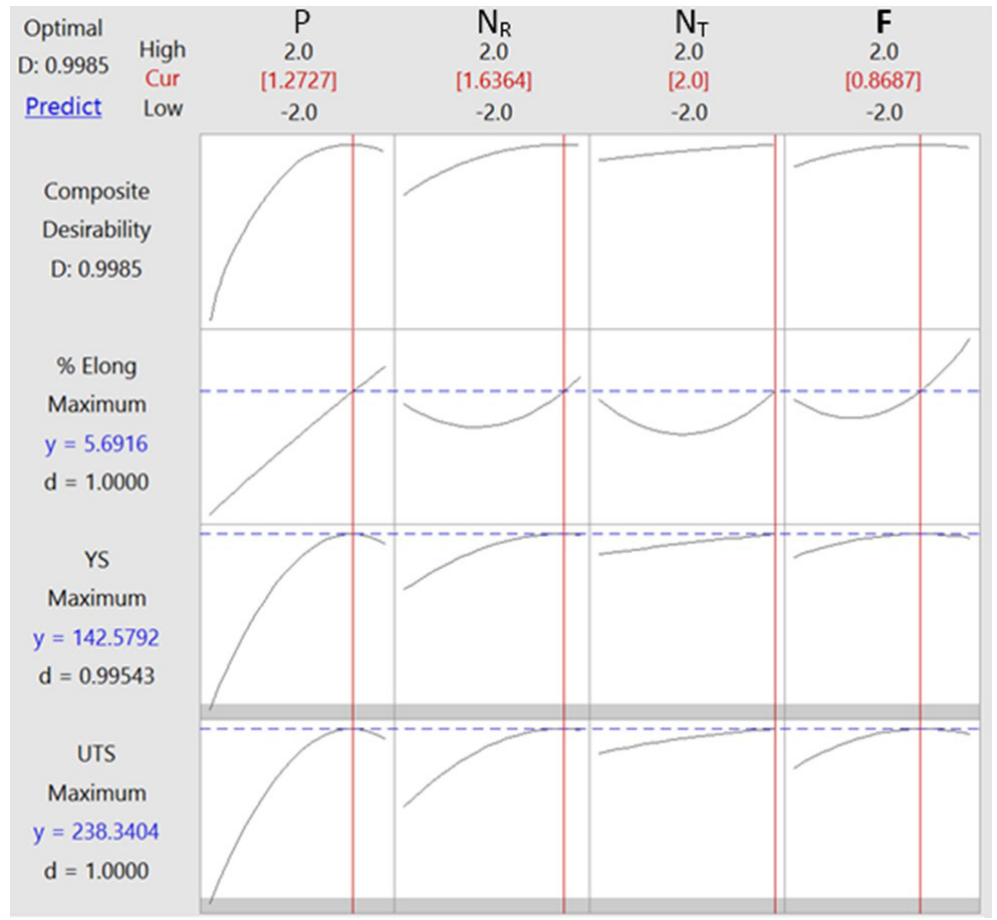

Fig. 10. Ideal Plots for the mechanical properties of welded AZ91C specimen

Minitab analytical software, and Fig. 10 illustrates the established ideal plots.

Table 5 describes in detail the predicted optimum input FSW process parameters required for obtaining good quality welded joints, including the type of pin profiled tool to be employed, the speed at which that tool must be rotated during welding, the amount of axial force to be exerted on the workpiece and the rate at which that FSW tool must travel over the workpiece. In other words, for obtaining an improved and preferable tensile strength of $238.34 \mathrm{MPa}$ in the fabricated AZ91CMg alloy joints, it is predicted using the $3 \mathrm{D}$ graphs, that, a tool with taper cylindrical pin geometry must be employed at $1045.46 \mathrm{rpm}$, it should travel over the AZ91C specimen at $1.5 \mathrm{~mm} / \mathrm{s}$, employing a $4.87 \mathrm{kN}$ force (axially). Under the abovementioned combination of FSW process parameters, it is predicted that the fabricated joints would exhibit a yield strength of $142.58 \mathrm{kN}$, together with a percentage of elongation of 5.69.

Six AZ91C Mg alloy welded specimen were fabricated using input parameter combinations described in Table 6 . The obtained welded joints were free from flaws and exhibited mechanical properties, nearer to the predicted values, which indirectly reveals 
Table 5. Description of the predicted optimum factors of FSW process

\begin{tabular}{lcccccc}
\hline Tool pin profile & Rotational speed [rpm] & Tool traversing speed [mm/s] & Axial force [kN] & UTS [MPa] & Yield [MPa] & Elongation [\%] \\
\hline Taper cylindrical & 1045.46 & 1.5 & 4.87 & 238.34 & 142.58 & 5.69 \\
\hline
\end{tabular}

Table 6. Comparison of the confirmatory experimental results with that of the results of the predicted values

\begin{tabular}{|c|c|c|c|c|c|c|c|c|c|c|c|c|c|}
\hline \multirow{2}{*}{$\begin{array}{l}\text { Trial } \\
\text { run }\end{array}$} & \multicolumn{4}{|c|}{ FSW Parameter } & \multicolumn{3}{|c|}{ UTS } & \multicolumn{3}{|c|}{ Yield Strength } & \multicolumn{3}{|c|}{ \% Elongation } \\
\hline & $P$ & $N_{R}$ & $N_{T}$ & $F$ & Exp & Predicted & $\begin{array}{l}\% \text { of } \\
\text { Error }\end{array}$ & Exp & Predicted & $\begin{array}{l}\% \text { of } \\
\text { Error }\end{array}$ & Exp & Predicted & $\begin{array}{l}\% \text { of } \\
\text { Error }\end{array}$ \\
\hline 1 & 1 & -1 & 0 & -1 & 218 & 209.55 & -3.88 & 124 & 121.19 & -2.27 & 3.94 & 4.25 & 7.87 \\
\hline 2 & 2 & 1 & 2 & 1 & 232 & 231.27 & -0.31 & 137 & 136.45 & -0.40 & 5.63 & 5.89 & 4.62 \\
\hline 3 & 1 & 2 & -1 & 2 & 217 & 221.27 & 1.97 & 131 & 129.08 & -1.47 & 5.61 & 5.88 & 4.81 \\
\hline 4 & 0 & 1 & 2 & 0 & 225 & 223.25 & -0.78 & 129 & 127.04 & -1.52 & 4.62 & 4.42 & -4.33 \\
\hline 5 & -1 & 2 & -1 & 0 & 183 & 185.87 & 1.57 & 90 & 92.64 & 2.93 & 4.23 & 4.12 & -2.60 \\
\hline 6 & $\begin{array}{c}\text { Taper } \\
\text { cylindrical }\end{array}$ & $\begin{array}{c}1045.46 \\
\text { rpm }\end{array}$ & $\begin{array}{c}1.5 \\
\mathrm{~mm} / \mathrm{s}\end{array}$ & $\begin{array}{c}4.87 \\
\mathrm{kN}\end{array}$ & 239 & 238.34 & -0.28 & 142 & 142.58 & 0.41 & 5.55 & 5.69 & 2.52 \\
\hline
\end{tabular}
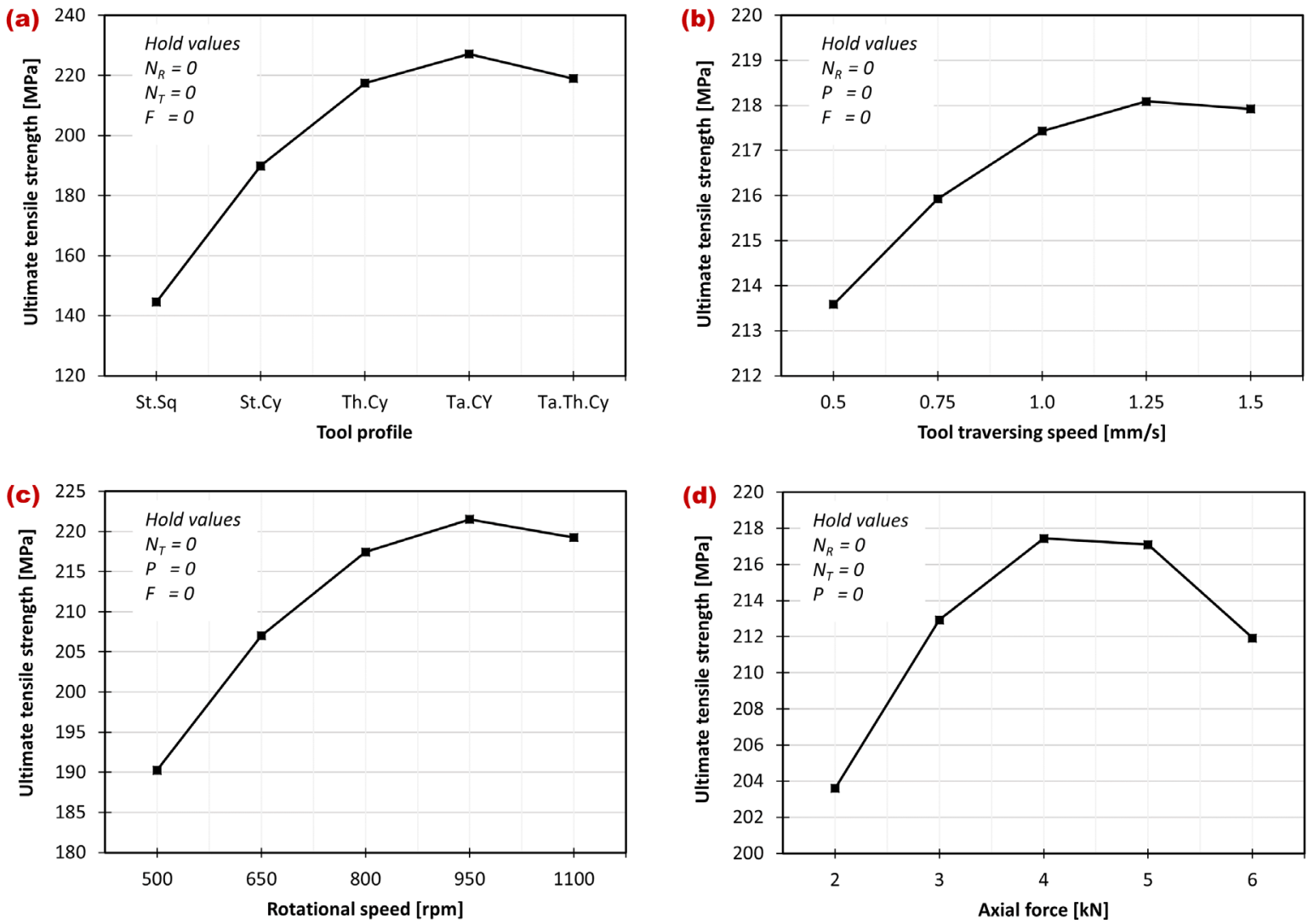

Fig. 11. Direct impacts of a) tool pin geometry, b) rotating speed, c) tool traversing speed, and d) axial force on mechanical strength of welded joints of AZ91C Mg alloy

their precise conformity with the anticipated software values.

\subsection{Analysis of Direct impact of Process Parameters}

Fig. 11 illustrates the direct impacts of those input FSW parameters on the mechanical strength of the
AZ91C Mg alloy welded specimen. The mechanical strength of the welded joints increases directly with the rise in tool traversing speed, axial force, and rotating speed. Then, they are observed to decline, once they reach their optimum high values. The graphs reveal that the axial force and rotating speed have a significant part in influencing the strength of 
the welded joints of $\mathrm{AZ91C} \mathrm{Mg}$ alloy, along with the tool pin geometry.

The tool with taper cylindrical pin geometry was observed to exhibit the highest value of mechanical strength and, at the same time, it can be seen that the straight square pin profiled FSW tool exhibits minimum values of the ultimate tensile strength. This is mainly because geometry of the tool pin plays a vital role in deciding the shear stress, thereby contributing directly for the frictional heat generation within the region of the weld (joint region). When the consolidation of the plasticized material occurs layer by layer, due to lack of sufficient volume of heat, it drastically reduces the joint strength.

Likewise, both lower and higher speeds of tool rotation as well as tool traversing speeds have resulted in generation of lower and higher volumes of frictional heat respectively, thereby leading to phenomenon of poor bonding. From these facts, it is obvious that perfect and suitable volume of heat (due to friction) gets generated only at optimized values of rotating speed of tool (1045 rpm), $1.5 \mathrm{~mm} / \mathrm{s}$ traversing speed, by employing a tool with taper cylindrical pin geometry and by exerting a $4.87 \mathrm{kN}$ axial force. This ideal volume of generated heat facilitates the flow of plasticized material in a uniform manner, enables the diffusion of the materials in the weld regions in a preferable manner, recrystallizes them perfectly, thereby producing defect-free $\mathrm{AZ91C} \mathrm{Mg}$ alloy joints.

\section{CONCLUSIONS}

This experimental investigation and analysis were carried out to determine the optimized values for various friction stir welding process parameters, essential for fabricating producing defect-free AZ91C $\mathrm{Mg}$ alloy joints. The various parameters of the FSW technique taken into during this investigational analysis include the rotating tool speed, the axial force applied, tool traversing speed and the tool's pin geometry. The obtained experimental results and observations from this investigation are listed below:

- Regression quadratic equations and empirical relationships were established to determine and predict the responses (i.e., mechanical properties) for AZ91C Mg alloy joints fabricated using FSW technique.

- The established quadratic regression model was found to be efficient in determining the responses of the FSWed AZ91C Mg allot joints in the range of $+10 \%$ of their actual experimental values at a $95 \%$ level of confidence, and experimental trial runs were performed to confirm the predicted results.

- 3D response surface charts illustrating the influence of input parameters on the mechanical properties and the direct impact plots representing the individual impact of these parameters on mechanical strength were generated and analysed in detail.

- The tool with taper cylindrical pin geometry fabricated joints with larger tensile strength values leading to high-quality defect-free AZ91C $\mathrm{Mg}$ alloy joints. This was mainly due to the generation of an ideal volume of heat generation, unique pulsating effect and thereby leading to enhanced flow of the plasticized material uniformly.

- $\quad$ AZ91C Mg alloy joints obtained using the tool having taper cylindrical pin geometry, employed at $1045 \mathrm{rpm}$, along a $1.5 \mathrm{~mm} / \mathrm{s}$ tool travelling speed, under the exertion of a $4.87 \mathrm{kN}$ axial force, were found to be free from flaws and naturally exhibited exceptional mechanical properties, especially higher values of ultimate tensile strength.

- The investigational study of the micro and SEM images revealed that the grains in the zone of nugget have been completely remodelled into homogenous, uniformly distributed, refined grains, which in turn contributed to the exceptional mechanical properties.

- Six AZ91C Mg alloy joints were fabricated employing the generated optimized input parameters. All the six joints were examined, and the observations revealed that they are completely free from defects, which proves their precise conformity with the generated values.

\section{REFERENCES}

[1] Vysotskiy, I., Malopheyev, S., Rahimi, S., Kaibyshev, R. (2019). Unusual fatigue behavior of friction-stir welded Al-Mg-Si alloy. Materials Science and Engineering: A, vol. 760, p. 277-286, DOl:10.1016/j.msea.2019.06.005.

[2] He, W., Zheng, L., Xin, R., Liu, Q. (2017). Microstructure-based modeling of tensile deformation of a friction stir welded AZ31 Mg alloy. Materials Science and Engineering: A, vol. 687, p. 63-72, D0l:10.1016/j.msea.2017.01.053.

[3] Arora, H.S., Singh, H., Dhindaw, B.K. (2013). Wear behaviour of a $\mathrm{Mg}$ alloy subjected to friction stir processing. Wear, vol. 303, no. 1-2, p. 65-77, D0l:10.1016/j.wear.2013.02.023.

[4] Sevvel, P., Satheesh, C., Jaiganesh, V. (2018) Influence of tool rotational speed on microstructural characteristics of dissimilar Mg alloys during friction stir welding. Transactions of 
the Canadian Society for Mechanical Engineering, vol. 43, no. 1, p. 132-141, D0I:10.1139/tcsme-2018-0037.

[5] Jeon, C.-S., Hong, S.-T., Kwon, Y.-J., Cho, H.-H., Han, H.N. (2012). Material properties of friction stir spot welded joints of dissimilar aluminum alloys. Transactions of Nonferrous Metals Society of China, vol. 22, suppl. 3, p. s605-s613, D0l:10.1016/ S1003-6326(12)61772-5.

[6] Derazkola, H.A., Elyasi, M. (2018). The influence of process parameters in friction stir welding of Al-Mg alloy and polycarbonate. Journal of Manufacturing Processes, vol. 35, p. 88-98, D0l:10.1016/j.jmapro.2018.07.021.

[7] Sevvel, P., Jaiganesh, V. (2017). Influence of the arrangement of materials and microstructural analysis during FSW of AZ80A \& AZ91C Mg alloys. Archives of Metallurgy and Materials, vol. 62, no.3, p. 1795-1801, D0I:10.1515/AMM-2017-0272.

[8] Ram Kumar, S., Duraiselvam, M., Sevvel, P. (2020). Acoustic emission based deep learning technique to predict adhesive bond strength of laser processed CFRP composites. FME Transactions, vol. 48, no. 3, p. 611-619, D0l:10.5937/ fme2003611S.

[9] Hou, L., Yu, J., Zhang, D., Zhuang. L., Zhou, L., Zhang. J. (2017). Corrosion behavior of friction stir welded Al-Mg-(Zn) alloys. Rare Metal Materials and Engineering, vol. 46, no. 9, p. 24372444, D0I:10.1016/S1875-5372(17)30212-6.

[10] Dhanesh Babu, S.D., Sevvel, P., Senthil Kumar, R. (2020). Simulation of heat transfer and analysis of impact of tool pin geometry and tool speed during friction stir welding of AZ80A Mg alloy plates. Journal of Mechanical Science and Technology, vol. 34,p. 4239-4250, D0l:10.1007/s12206-0200916-7.

[11] Kim, W.J., Yoo, S.J., Kim, H.K. (2008) Superplastic microforming of Mg-9Al-1Zn alloy with ultrafine-grained microstructure. Scripta Materialia, vol. 59, no. 6, p. 599-602, DOI:10.1016/j.scriptamat.2008.05.014.

[12] Sevvel, P., Dhanesh Babu, S.D., Senthil Kumar, R. (2020). Peak temperature correlation and temperature distribution during joining of AZ80A Mg alloy by FSW - A numerical and experimental investigation. Strojniški vestnik - Journal of Mechanical Engineering, vol. 66, no. 6, p. 395-407, DOI:10.5545/sv-jme.2020.6566.

[13] Thangaiah Stephan, I.S., Sevvel, P., Satheesh, C., Jaiganesh, V. (2017). Investigation on the impingement of parameters of FSW process on the microstructural evolution and mechanical properties of AZ80A Mg alloy joints. FME Transactions, vol. 46, no. 1, p. 23-32, D0I:10.5937/fmet1801023T.

[14] Khodabakhshi, F., Aghajani Derazkola, H., Gerlich, A.P. (2020). Monte Carlo simulation of grain refinement during friction stir processing. Journal of Materials Science, vol. 55, p.1343813456, DOI:10.1007/s10853-020-04963-2.

[15] Sevvel, P., Srinivasan, D., Balaji, AJ., Gowtham, N., KalyanaVaradhan, V.G., Kumaresh, P., Kishore Bajrang, M. (2019). Design \&fabrication of innovative desktop 3D printing machine. Materials Today: Proceedings, vol. 22, p. 32403249, D0l:10.1016/j.matpr.2020.03.284.

[16] Richmire, S., Hall, K., Haghshenas, M. (2018). Design of experiment study on hardness variations in friction stir welding of AM60 Mg alloy. Journal of Magnesium and Alloys, vol. 6, no. 3, p. 215-228, D0l:10.1016/J.jma.2018.07.002.
[17] Yuan, S.J., Hu, Z.L., Wang, X.S. (2012). Formability and microstructural stability of friction stir welded Al alloy tube during subsequent spinning and post weld heat treatment. Materials Science and Engineering: A, vol. 558, p. 586-591, DOI:10.1016/j.msea.2012.08.056.

[18] Sevvel, P., Jaiganesh, V. (2017). Investigation on evolution of microstructures and characterization during FSW of AZ80A Mg alloy. Archives of Metallurgy and Materials, vol. 62, no.3, p. 1779-1785, D0I:10.1515/amm-2017-0270.

[19] Derazkola, HA, Khodabakhshi, F. (2019). Underwater submerged dissimilar friction-stir welding of AA5083 aluminum alloy and A441 AISI steel. The International Journal of Advanced Manufacturing Technology, vol. 102, p. 43834395, D0l:10.1007/s00170-019-03544-1.

[20] Liang, X., Li, H., Li, Z., Hong, T., Ma, B., Liu, Y. (2012). Study on the microstructure in a friction stir welded 2519-T87 Al alloy. Materials and Design, vol. 35, p. 603-608, D0l:10.1016/j. matdes.2011.10.009.

[21] Sevvel, P., Stephan Thangaiah, I.S., Mars Mukesh, S., Mohammed Anif, G. (2015). Laboratory scale testing of thermoelectric regenerative braking system. International Journal of Vehicle Structures \& Systems, vol. 7, no. 4, p. 157 160, D0I:10.4273/ijvss.7.4.08.

[22] Derazkola, H.A., Simchi, A. (2018). Experimental and thermomechanical analysis of the effect of tool pin profile on the friction stir welding of poly(methyl methacrylate) sheets. Journal of Manufacturing Processes, vol. 34, part A, p. 412423, D0I:10.1016/j.jmapro.2018.06.015.

[23] Meng, X., Jin, Y., Ji, S., Yan, D. (2018) Improving friction stir weldability of $\mathrm{Al} / \mathrm{Mg}$ alloys via ultrasonically diminishing pin adhesion. Journal of Materials Science and Technology, vol. 34, no. 10, p.1817-1822, D0l:10.1016/J.jmst.2018.02.022.

[24] Elangovan, K., Balasubramanian, V., Valliappan, M. (2008). Influences of tool pin profile and axial force on the formation of friction stir processing zone in AA6061 aluminium alloy. The International Journal of Advanced Manufacturing Technology, vol. 38, p. 285-295, DOl:10.1007/s00170-007-1100-2.

[25] Jaiganesh, V., Nagarajan, P.K., Sevvel, P., Dhileep Kumar, J., Manivannan, S. (2016). Impact of tool pin geometry and optimized process parameters on mechanical properties of friction stir welded AZ80A Mg alloy. Materials Science Forum, vol. 886, p. 151-155, D0l:10.4028/www.scientific.net/ MSF.866.151.

[26] Razal Rose, A., Manisekar, K., Balasubramanian, V. (2011). Effect of axial force on microstructure and tensile properties of friction stir welded AZ61A magnesium alloy. Transactions of Nonferrous Metals Society of China, vol. 21, no. 5, p. 974-984, DOI:10.1016/S1003-6326(11)60809-1.

[27] Nan Xu, N., Song, Q., Fujii, H., Bao, Y., Shen, J. (2018). Mechanical properties' modification of large load friction stir welded AZ31B Mg alloy joint. Materials Letters, vol. 219, p. 9396, D0I:10.1016/j.matlet.2018.02.0993.

[28] Karthikeyan, P., Thiagarajan, D., Mahadevan, K. (2014). Study of relation between welding and hardening parameters of friction stir welded aluminium2024 alloy. Procedia Engineering, vol. 97, p.505-512, D0l:10.1016/j. proeng.2014.12.275. 
[29] Sevvel, P., Satheesh, C., Senthil Kumar, R. (2019). Generation of regression models and multi-response optimization of friction stir welding technique parameters during the fabrication of AZ80A Mg alloy joints. Transactions of the Canadian Society for Mechanical Engineering, vol. 44, no.2, p. 311-324, D0l:10.1139/tcsme-2019-0162.

[30] Kesharwani, R.K., Panda, S.K., Pal, S.K. (2014). Multi-objective optimization of friction stir welding parameters for joining of two dissimilar thin aluminum sheets. Procedia Materials Science, vol. 6, p. 178-187, D0l:10.1016/j.mspro.2014.07.022.

[31] Eyvazian, A., Hamouda, A., Tarlochan, F., Derazkola, H.A., Khodabakhshi, F. (2020). Simulation and experimental study of underwater dissimilar friction-stir welding between aluminium and steel. Journal of Materials Research and Technology, vol. 9, no. 3, p. 3767-3781, D0l:10.1016/j. jmrt.2020.02.003.

[32] Sevvel, P., Satheesh, C. (2018). Role of tool rotational speed in influencing microstructural evolution, residual-stress formation and tensile properties of friction-stir welded AZ80A Mg alloy. Materials and Technology, vol. 52, no. 5, p. 60-614, DOI:10.17222/mit.2017.213.

[33] Derazkola, H.A., Aval, H.J., Elyasi, M. (2015). Analysis of process parameters effects on dissimilar friction stir welding of AA1100 and A441 AISI steel. Science and Technology of Welding and Joining, vol. 20, no. 7, p. 553-562, Dol:10.1179 /1362171815Y.0000000038.
[34] Sevvel, P., Jaiganesh, V. (2016). Impact of process parameters during friction stir welding of AZ80A Mg alloy. Science and Technology of Welding and Joining, vol. 21, no. 2, p. 83-90, DOl:10.1179/1362171815Y.0000000068.

[35] Derazkola, A.H., Khodabakhshi, F. (2019). Intermetallic compounds (IMCs) formation during dissimilar friction-stir welding of AA5005 aluminum alloy to St-52 steel: numerical modeling and experimental study. The International Journal of Advanced Manufacturing Technology, vol. 100, p. 2401-2422, DOI:10.1007/s00170-018-2879-8.

[36] Elyasi, M., Derazkola,, H.A.Hosseinzadeh, M. (2016). Investigations of tool tilt angle on properties friction stir welding of A441 AISI to AA1100 aluminium. Proceedings ofthe Institution of Mechanical Engineers, Part B: Journal of Engineering Manufacture, vol. 230, no. 7, p. 1234-1241, DOl:10.1177/0954405416645986.

[37] Giridharan, K., Sevvel, P., Senthilnathan, K., Muthukumaran, S., Padmanabhan, S. (2019). Experimental study on mechanical properties of friction stir welded dissimilar joints of aluminiumalloys AA8011-AA6082. International Journal of Vehicle Structures and Systems, vol. 11, no. 2, p. 135-139, DOI:10.4273/ijvss.11.2.04.

[38] Derazkola, A.H. (2019). Simulation of tool rotation and travelling speed effects on friction stir welding of Ti-6Al4V. Journal of Modern Processes in Manufacturing and Production, vol. 8, no. 2, p. 39-56. 